\title{
ReAl-time Process manager and ITS APPLICATION IN ROBOtics
}

\author{
U. Ceseña' \& R. Muraoka² \\ ${ }^{1}$ Instituto de Astronomía de la Universidad Nacional Autónoma de México (IA - UNAM), \\ Departamento de Computo, Km. 103 Carretera Tijuana-Ensenada, Ensenada, B. C., México \\ Tel: (646) 1744580 Ext.: 243 e-mail: urania@astrosen.unam.mx \\ ${ }^{2}$ Centro de Investigación Científica y de Educación Superior de Ensenada (CICESE), \\ Departamento de Electrónica y Telecomunicaciones, Km. 107 carretera Tijuana - Ensenada, Ensenada, B. C., México \\ Received: June $28^{\text {th }} 2001$ and accepted June $6^{\text {th }} 2002$
}

\section{ABSTRACT}

The Real Time Process Manager consists of a graphic user interface that enables the user to generate programs for real time applications based on programs written in standard C, assigns priority and execution period to each program, and also interchanges data among them.

The functionality of this Process Manager was tested in computer control system of direct drive robot arm of CICESE research center.

\section{RESUMEN}

El administrador de procesos en tiempo real consiste en una inferfaz gráfica de usuario que permite a éste general programas para aplicaciones en tiempo real basadas en códigos escritos en $\mathrm{C}$ estándar, asignando prioridad y tiempo de ejecución a cada programa e intercambiar datos entre ellos. La funcionalidad de este administrador de procesos fue probada en el sistema de control computarizado de un brazo robótico en el CICESE.

KEYWORDS: Real-time, process, priority, execution period, real-time operating system, robotics.

\section{INTRODUCTION}

The operative systems have evolved over the years. With this evolution there have appeared operative systems with requirements or new characteristics. Among them we can mention: the operative systems to control several computers (distributed systems), operative systems that work with several processors (symmetrical processing), systems with requirements at the managing of the time (real time operative systems), etc.

Calls "system of real time" to the software that develops to be executed over an real time operative system. This type of software must be capable to react in precise times to external events. As consequence, the behavior of these systems depends not only on the results computation obtained but also from the time in which these results are produced.

One of the areas where the use of the real time operative systems (RTOS), is increasing permanently robotics. The robotics is focused on the study of robots, where a robot is an electromechanical system able to make some tasks in automatic way and that can be rescheduled to execute other actions. 


\subsection{Real time operative systems}

Real time operative system (RTOS), has been designed to operate under time restrictions. An RTOS is able to guarantee the execution of the processes in the required times. The Real time processing must be accurately, since it depends not only on the logical results of a calculation, but also from the instant in which this is produced.

\section{DEVELOPMENT OF THE REAL TIME PROCESS MANAGER}

The system of software Real Time Process Manager (RTPM) was implemented on the operative system QNX, that bases on a microkernel architecture that implements four services: scheduling of processes, interprocesses communication, communication of network of low level and use of interruptions. The tasks corresponding to the handling of devices and the file systems are implemented as processes of user [9].

The characteristics of the RTPM are:

- To manipulate and to coordinate processes of real time, as well as, the possibility of transferring information between the processes.

- To transform a program based on language C standard (user's program), to a program with characteristics of real time (program of real time) through the incorporation of a priority and period of execution.

- It can be used in any area where it is required to take the control of an external device in real time and in addition to work with several programs that transfer information among them.

2.1 General operation of the system

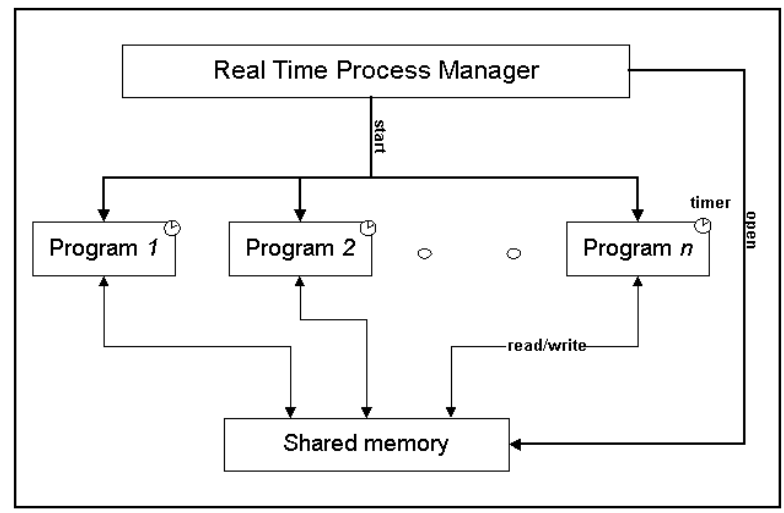

Figure 1, General diagram of the RTPM.

The RTPM makes two basic functions:

- $\quad$ To use the information contained in user's program (with the typical structure in language $\mathrm{C}$ ), to generate a new program that will count on the characteristics to be executed as a process of real time in QNX. To these programs generated by the RTPM, it names " program of real time ".

- $\quad$ Once created the programs of real time, the RTPM must start and finish their execution, and provide means that the programs can share information among them. 
All this is transparent to the user, who will open the programs of the user and will establish the relations among them (if he/she wants to) and will start its execution.

In the figure 1, the form is observed in which the problem of sharing information between the processes, was solved. Before executing the programs, the RTPM creates a section of shared memory that is accessed by all the processes, so if one of them modifies the value of a variable in shared memory, that change is automatically seen by all the other processes.

\subsection{Description of the RTPM}

The RTPM works in similar way in the environment Windows of Microsoft. Like in Windows all the functions can be selected using the mouse.

The graphical interface of RTPM is divided in three sections (figure 2):

- $\quad$ Bar of title: this section contains the name of the system "Manejador de Procesos " and the icons of to minimize "-" and to close " $\mathrm{X}$ " the window.

- $\quad$ Bar of menus: it contains two submenus:

- Menu "Opciones": it contains three submenus: Ruta (it allows the user to change the working directory), Inicializar (to start a session), Salir (it finishes the execution of the RTPM and of all the programs open with the RTPM).

- Menu "Lenguaje": it contains two submenus English and Spanish which are used to change all the labels in the RTPM to the language selected. Default all the labels are in Spanish.

Section of folders: it is the main section of the RTPM, because it is in this section where the most important operations of the system are carried out. The folders are: "Seleccionar", "Relacionar", "Variables" and "Acciones".

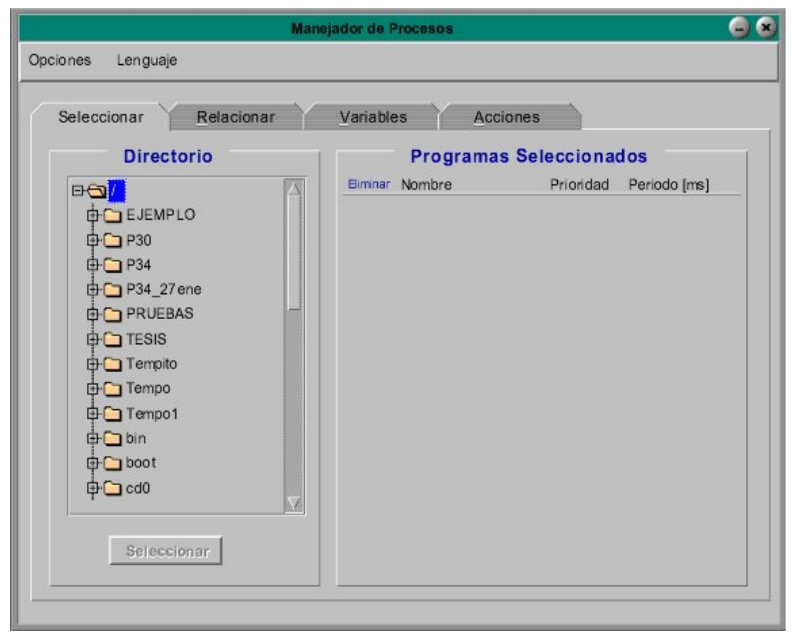

Figures 2. Folder selection of programs.

The operation of the folders are described next:

a) Seleccionar: This folder is composed by two parts (figure 2):

I. Directorio: it allows the user to select the programs to be executed. Such programs must have the structure of user program. 
II. Programas Seleccionados: it shows the list of the programs selected by the user. The list is composed by four columns:

III. Eliminar: to each program that is in the list there is a rhombus corresponds that selected to eliminate this program from the list.

IV. Nombre: contains the names of the selected programs.

V. Prioridad: allows to assign a priority to each program that appears in the list.

VI. Periodo: allows to assign a period of execution (in milliseconds) to each program that appears in the list. When the user selects a program in the Directorio section, the RTPM default assigns a 10 priority and a 100 milliseconds of period. These values are subject to changes depending on the necessities of the user.

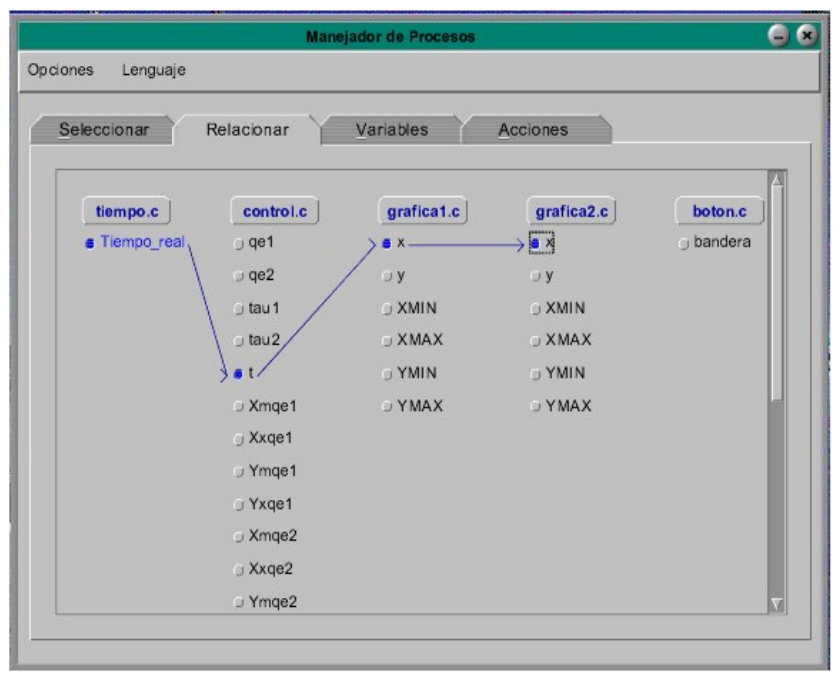

Figures 3. Folder: relation of variables.

b) Relacionar: The main function of this folder is to allow to establish the relations between the variables of the selected programs. The relations between variables are transferring information between the variables of the programs once they are put in execution by the RTPM (see figure 4).

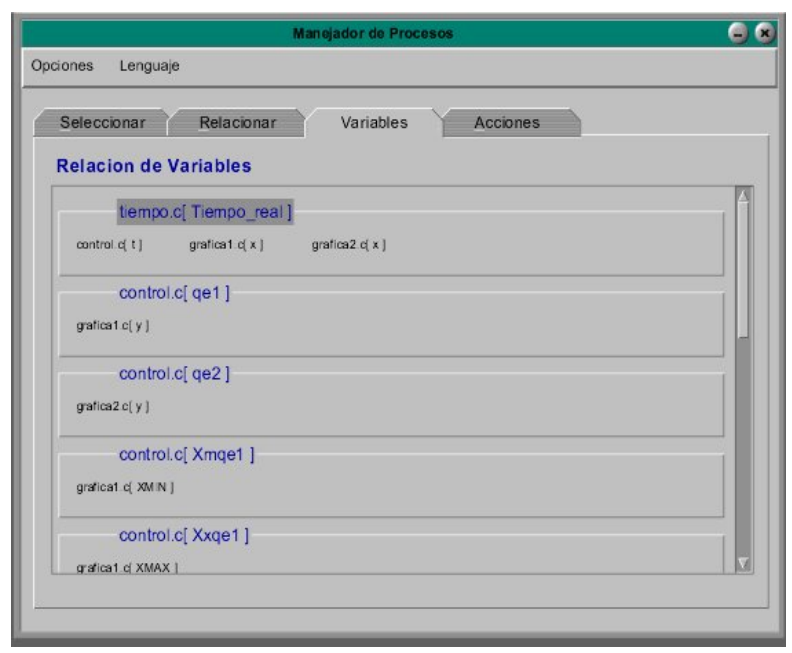


Figure 4. Folder to show relations between variables.

c) Variables: The information that shows this folder, corresponds to the relations of variables that were established in the folder Relacionar. The related variables are framed within a rectangle where the writing variable appears in the superior part of the rectangle and the reading variables appear within the rectangle (figure 4).

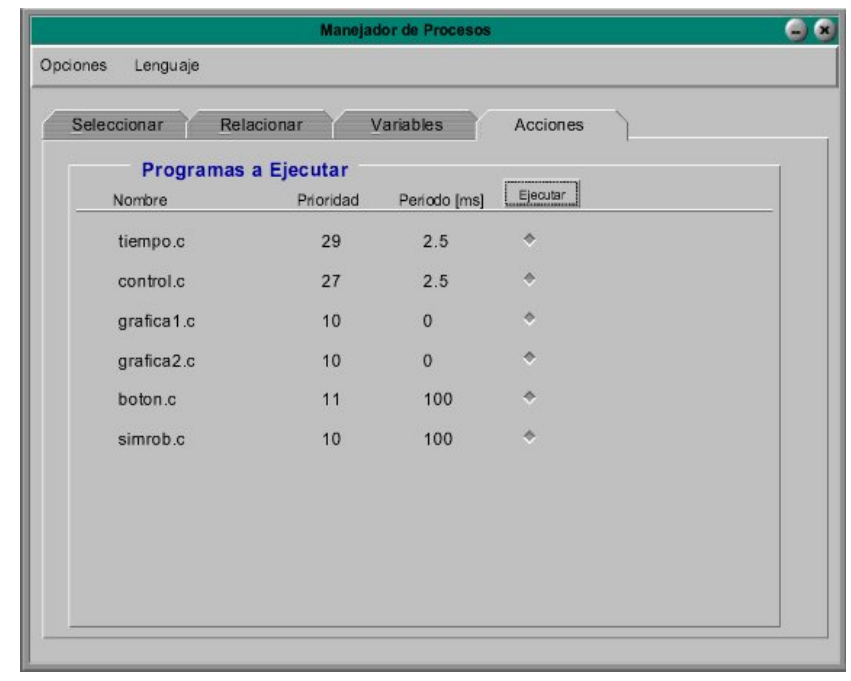

Figures 5. Folder for execution of programs.

d) Acciones: this folder provides to the user the average to put in execution the programs that were selected. In addition program gives the possibility him of stopping each one of them that were put in execution previously. The folder Acciones display to the user the following information (figure 5):

- Nombre: names of the selected programs.

- Prioridad: priorities that will be assigned to them to each one of the programs in run time.

- Periodo: period of each of the programs.

- Ejecutar: this column is headed by a button. That when is pressed, it will execute the programs (that appear in the list). For each program matches a rhombus, when it is pressed starts or stops the execution of the selected program.

\section{APPLICATION TO ROBOTICS}

The real time operative systems surge from the intersection of two great areas of knowledge, the engineering of computing systems and control engineering (figure 6) [2].

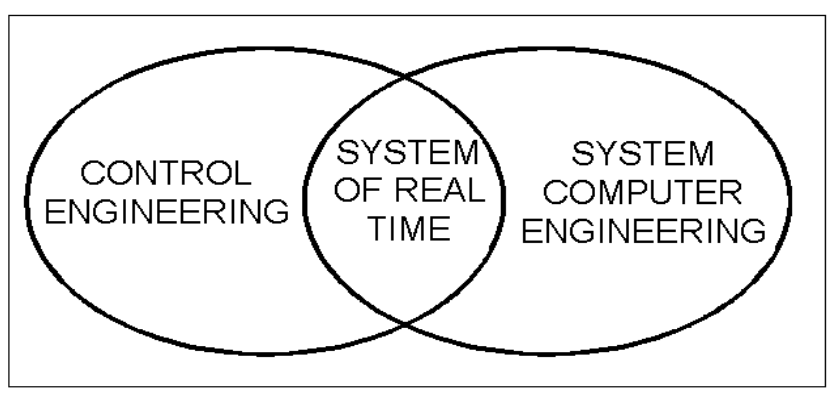


Figures 6. Position of the systems of real time.

It is comprehensible then that the use of the RTOS occurs in the robotics area. The robotics focuses to the study of robots, where a robot is an electromechanical system able to make some task automatic form and that can be rescheduled to execute other actions.

An important difficulty in robotics is the speed with which the algorithms must be executed and the necessity to interchange information in real time between them. For this reason the use of several processing which units interactor has to satisfy the requirements calculation in real time finds an immediate application in robotics. To prove the functionality of the RTPM, the following elements were used:

- Mechanical arm: It is a manipulative robot of two degrees of freedom, formed by two rotational motors of direct transmission, the one for the shoulder and the other one for the elbow, united by two links. The motors are operated with a signal of analogical voltage. Each of them consists of incremental optical coders.

- $\quad$ Data acquisition board: the MFIO-3A board, was used to establish the interface of communication between the system of software and the robot. It has three channels of 16-bit D/A entrances for three optical coders, 24 bits of digital programming of I/O and supports the standard bus of 16-bit ISA. The manufacturer of the board is A Precision MicroDynamics.

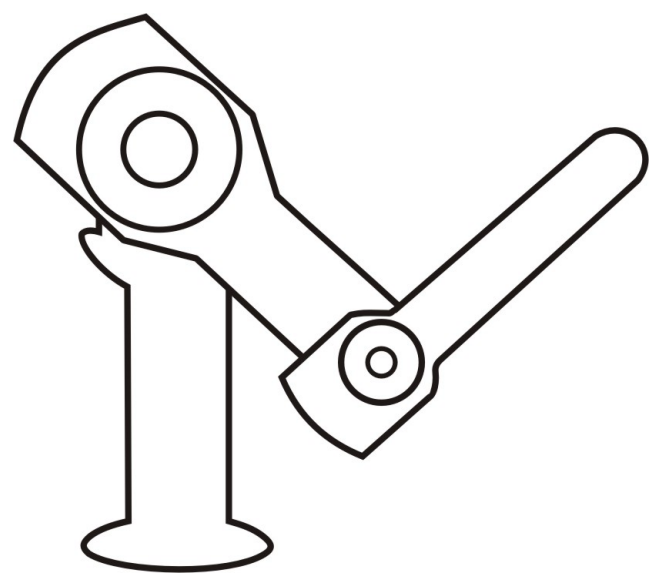

Figure 7 Diagram of the manipulative robot.

- $\quad$ Controller: It is the numerical algorithm that allows to manipulate a physical system in automatic form, when comparing the data obtained from one of the wished tasks. It is also known as control algorithm.

- $\quad$ Auxiliary programs: two programs were created to make graph of value at XY (grafica1.c and grafica2.c), a program that takes the account of the time (tiempo.c), another programs that contains drivers for the use of the card of data acquisition (mfiolib.h) and other and contains the control algorithm(control.c) and finally a program that creates a button (graphical window) to be pressed to send the mechanical arm to the original position(boton.c).

The programs in run time, realize the following tasks: to transfer information between the programs, to execute with a period and a priority, to control the mechanical arm and to make graphs of the variables indicated by the user (positions, errors, etc.) and when pressing the button with the label "Ir a casa" (this button creates the program boton.c) the arm returns to the origin position. 


\subsection{General diagram of the application to robotics}

Figure 8 shows the general way in wich the RTPM a an application in the robotics area is used, which consists of using the system as a tool of experimentation of algorithms control for the manipulation of robots. Next each one of the blocks of the figure is described.

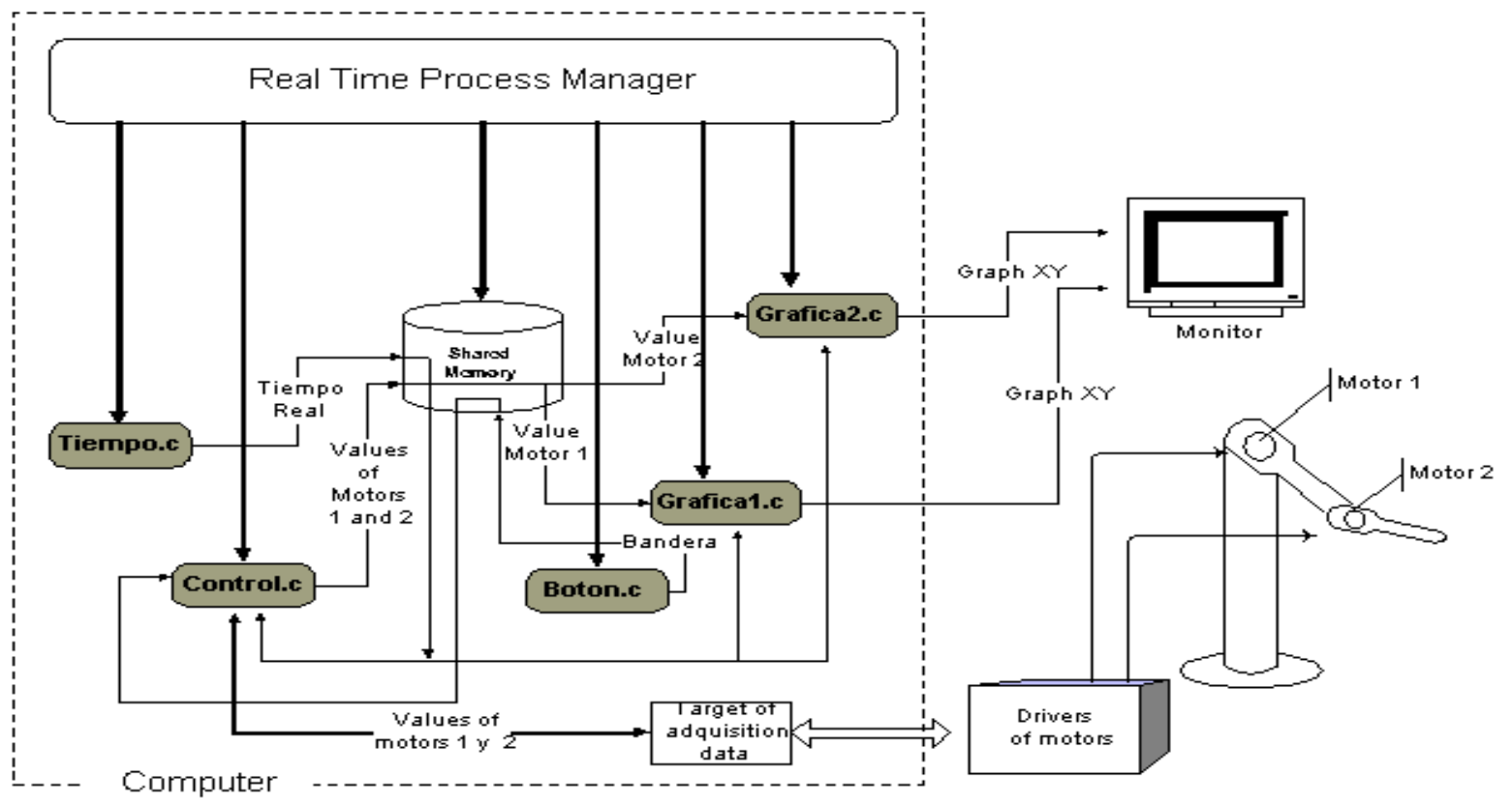

Figure 8. General diagram of the application to robotics.

- $\quad$ Tiempo.c: this program has the task of taking the account of the passed real time since it initiates the execution of the algorithm. It assigns the highest priority (29) because the passed time is of extreme importance for the control algorithm, as well as, for the programs that makes the graphs. It assigns to it period of execution of 2.5 milliseconds.

- Control.c: this is the program that contains the control algorithm, which allows the execution and manipulation of the robot. In general it carries out the following actions: reads the position of the motor of each of the joints of the robot, estimates the speed of every joint, executes a control algorithm to determine necessities for each one of the motors and apply the pairs calculated to the motor through the acquisition board. Once realized the wished task, the robot must be returned to its original position and changing the algorithm of control to one that leads the robot to its home position. In order to obtain this it is necessary to use a variable that changes its value to indicate the change of control algorithm. This program is executed with a period of 2.5 milliseconds.

- $\quad$ Grafica1.c: the goal of this program is to open on the screen a graph with the variables that reads from the shared memory, as they are the coordinated $X-Y$ and the maximum and minimum values of the scales of the graph. The priority 10 is assigned to it. That is the value assigned by default by RTOS QNX.

- $\quad$ Grafica2.c: This program is a copy of the program grafica1.c, with different name. Thus the RTPM cannot select two programs that are called equal. Grafica1.c and grafica2.c they both are asynchronous programs (without period of execution). 
- $\quad$ Boton.c: its function consists in opening on the screen a button with the label "Ir a Casa", that when it is pressed it changes the value of a flag then it will be read for control.c through the share memory. The priority assigned to this program is 11 and period of execution to 100 milliseconds.

- Mfiolib.h: it is a head file that contains the functions for the use of the data acquisition MFIO-3A board.

- Librerias gnx.h: it is a head file that contains functions that use the programs of real time generated by the RTPM.

\section{CONCLUSIONS}

The objective of the present work was the design of an application of software that allowed to use the concepts of processing in real time, to evaluate its benefits in the robotics area. The first step was the study of the theory on real time operative systems, choosing the RTOS QNX. The developed application of software receives the name of Real Time Process Manager (RTPM) and has the following characteristics: allows the execution of several programs like processes of real time "simultaneously", handles process of type graphical (that present a graphical window) and type text (that do not show any graph), offers the possibility to execute programs of synchronous form (the program is executed in periodic form) or asynchronous one (the program is executed whenever the processor is released of the attention to the synchronous processes), creates a space of common memory for the processes and this information can be shared and presents to the user a friendly easy use environment.

In order, to evaluate the functionality of the RTPM, in the area of robotics, it uses a mechanical arm of robotics laboratory of CICESE. A group of programs were designed for the execution of the control algorithm and makes graphs of results.

The most important advantages of the Real Time Process Manager are the following ones:

- It is a software system that is considered of general intention.

- It offers support as a tool of experimentation of control algorithms.

\section{ACKNOWLEDGEMENTS}

This document is the result of the master thesis "Real time operative systems and their potential applications in robotics", developed in CICESE research center, under the direction of the Ph. Rafael Kelly Martínez of the electronics and telecommunications department. We thank for his time and his valuable ideas. Also, we appreciate the help of mto. Ricardo Campa to convert this project into a reality.

\section{REFERENCES}

[1] Aranda J. y Vignoni R., "Sistemas Operativos de Tiempo Real. Notas del curso. IV Jornadas Iberoamericanas de Automática". (Antigua, Guatemala. Septiembre), 60, (1997).

[2] Arzen K., "Real-Time Systems, Lecture 1 (Engineering Course)", http://control.Ith.se/, (1999).

[3] Barabanov M. y Yodaiken V., "Introducing Real-Time Linux", http://www.rtlinux.cs.nmt.edu, (1996).

[4] Butazzo G., "Hard Real-Time Computing Systems", Kluwer Academic Publishers, 356, (1997).

[5] Gallmeister B., "POSIX.4 Programming for the Real World". O'Reilly\Associates, Inc., 586,(1995).

[6] Jaramillo F., "Plataforma para el ensayo de algoritmos de control para un robot manipulador", Tesis de maestría, CICESE, (1999).

[7] Microtec Division, "VRTX Real-Time Operating System”, http://www.mentorg.com/ (1998). 
[8] Pressman R., "Ingeniería del software", McGraw Hill, 480,(1993).

[9] QNX, “QNX Operating System”, QNX Software System Ltd,120, (1997).

[10] Reyes F., "Control de un robot de transmisión directa de dos grados de libertad”, Tesis doctoral, CICESE, (1997).

[11] Ramos R., Costas C., Kang C.S., Son D.S. y Anigstein M., "Procesamiento distribuido en tiempo real. Aplicación a un controlador robótico, Memorias de la VII Reunión de trabajo en Procesamiento de la Información y Control (RPIC)", (San Juan, Argentina), 12,(1997).

[12] Stewart y Khosla, "Chimera Real-Time Operating System”, http://www.cs.cmu.edu/, (1997).

[13] Tanenbaum A., "Sistemas Operativos Modernos", Prentice Hall Hispanoamericana, (1993).

[14] VenturCom, "RTX 4.3 User's Guide”, VenturCom, Inc, (1999).

\section{Authors Biography:}

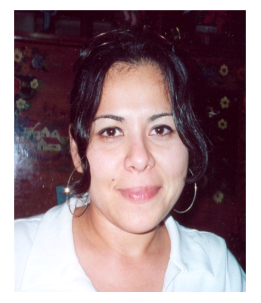

Urania Ceseña

M.Sc degree in Computer Science from Centro de Investigación Científica y Educación Superior de Ensenada (Centre of Scientific Research and Higher Education of Ensenada, Mexico), and her research areas include computers, robotics and security networks systems. She is working in Observatorio Astronómico Nacional del Instituto de Astronomía de la Universidad Nacional Autónoma de México (National Astronomy Observatory of Astronomy Institute of the Nationa Autonomous University of Mexico) as manager of computer center.

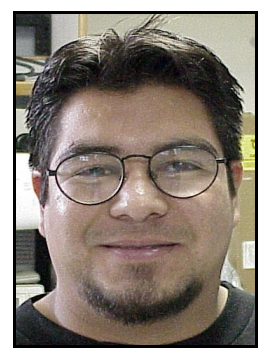

Ramon Muraoka

BSEE from the Universidad Autónoma de Baja California, México (Autonomous University of Baja California, Mexico). He provides Technical support for Electronics \& Telecommunications Department of Center of Scientific Research and Higher Education of Ensenada (CICESE). He has working in development of space optical communications systems. Currently is a student of a master of science degree at CICESE. 